\title{
Highly Active Antiretroviral Therapy-silver Nanoparticle Conjugate Alleviates Anxiety-like Behaviour in Streptozotocin-induced Diabetic Rats
}

Sodiq Kolawole Lawal ( $\sim$ lawalsodiq6@gmail.com )

University of KwaZulu-Natal

Samuel Oluwaseun Olojede

University of KwaZulu-Natal

Ayobami Dare

University of KwaZulu-Natal

Oluwaseun Samuel Faborode

University of KwaZulu-Natal

Edwin C. Stephen Naidu

University of KwaZulu-Natal

Carmen Olivia Rennie

University of KwaZulu-Natal

Onyemaechi Okpara Azu

University of Namibia

\section{Research Article}

Keywords: HAART, Prefrontal cortex, glial fibrillary acidic protein, silver nanoparticles, inflammation, and oxidative stress

Posted Date: November 1st, 2021

DOI: https://doi.org/10.21203/rs.3.rs-1025387/v1

License: (c) (1) This work is licensed under a Creative Commons Attribution 4.0 International License.

Read Full License 
Highly active antiretroviral therapy-silver nanoparticle conjugate alleviates anxiety-like behaviour in Streptozotocin-induced diabetic rats

Sodiq Kolawole Lawal ${ }^{1}$, Samuel Oluwaseun Olojede ${ }^{1}$, Ayobami Dare ${ }^{2}$, Oluwaseun Samuel

Faborode $^{2}$, Edwin C. Stephen Naidu ${ }^{1}$, Carmen Olivia Rennie ${ }^{1}$ and Onyemaechi Okpara Azu ${ }^{3}$

${ }^{1}$ Discipline of Clinical Anatomy, School of Laboratory Medicine \& Medical Sciences, Nelson

R Mandela School of Medicine, University of KwaZulu-Natal, 719 Umbilo Road, Durban, South Africa.

${ }^{2}$ Department of Physiology, School of Laboratory Medicine \& Medical Sciences, Westville Campus, University of KwaZulu-Natal, Durban, South Africa

${ }^{3}$ Department of Anatomy, School of Medicine, University of Namibia, Windhoek, Private bag 13301, Namibia

Corresponding author: LAWAL Sodiq Kolawole. Discipline of Clinical Anatomy, School of Laboratory Medicine and Medical Sciences, University of KwaZulu-Natal, Private Bag X 54001, Durban 4000, South Africa.

Email: lawalsodiq6@gmail.com,219083228@stu.ukzn.ac.za 


\begin{abstract}
Background: The inception of highly active antiretroviral therapy (HAART) has changed the management of human immunodeficiency virus (HIV) positive patients, and their life expectancy has improved. However, neurological complications associated with chronic HAART administration has not been fully addressed. Therefore, this study aimed to evaluate the potential benefits of silver nanoparticles (AgNPs) conjugates on the anxiogenic effects of HAART in type2 diabetic rats.
\end{abstract}

Methods: Forty-two (42) adult male Sprague-Dawley rats $(250 \pm 13 \mathrm{~g})$ were divided into nondiabetic and diabetic groups. After induction of diabetes, non-diabetic and diabetic animals were administered either with de-ionized water (DW), HAART (98.2 mg/kg, p.o) or AgNPs +HAART (24.5 mg/kg, i. p) for 8 weeks. Thereafter, metabolic biomarkers, oxidative injury, tissue inflammation, and behavioural changes were evaluated, while the prefrontal cortex was excised for neurochemical analysis.

Results: The HAART-treated diabetic rats showed a significant increase in blood glucose level, number of faecal pellets, malondialdehyde (MDA), and pro-inflammatory cytokines (TNF- $\alpha$, IL$1 \beta$ ) while locomotion, reduced glutathione (GSH), superoxide dismutase (SOD) activity, and PFCGFAP positive cells were significantly reduced compared with diabetic control. However, administration of AgNPs +HAART to diabetic rats significantly improved the blood glucose level, metabolic activities, SOD, GSH, PFC-GFAP positive cells while reducing MDA and anxiety-like behaviour in the open field test.

Conclusion: Administration of HAART aggravates anxiety-like behaviours and promotes neurotoxic effects in the PFC of diabetic rats. However, AgNPs +HAART alleviates the 
anxiogenic effects of HAART and preserves PFC-GFAP positive cells by reducing oxidative and neuroinflammatory injury.

Keywords: HAART, Prefrontal cortex, glial fibrillary acidic protein, silver nanoparticles, inflammation, and oxidative stress.

\section{Introduction}

The introduction of highly active antiretroviral therapy (HAART) has changed the diagnosis of the Human immunodeficiency virus (HIV) from a fatal disease into a chronically managed condition. Consequently, the life expectancy and the quality of life among the people living with HIV has since improved (Lewden et al., 2012). Despite the benefits of HAART, its long-term use and systemic exposure has been strongly linked with various metabolic disturbances such as diabetes and cardiovascular diseases (Nansseu et al., 2018). Previous studies have reported that initiation of antiretroviral therapy (HAART) increases the risk of diabetes mellitus (Ergin et al., 2020; Nansseu et al., 2018). The mechanism by which HAART causes diabetes has been attributed to excessive reactive oxygen species (ROS) production, leading to cell toxicity (Hulgan et al., 2003; Nsonwu-Anyanwu et al., 2017; Sharma, 2014). The increased ROS damage vital cellular components (like DNA, lipids, and proteins) in glucoregulatory tissues leading to nonresponsiveness to insulin or compromise insulin synthesis, thereby promoting hyperglycemia (Han, 2016). Also, HAART has been linked with mitochondrial damage and subsequently increases the risk of neuropathy and neuroinflammation (Lin et al., 2018; Lucas et al., 2011). Chronic administration of HAART to HIV positive patients has been reported to cause neuroinflammation, changes in astrocyte mitochondrial membrane and mitochondrial ROS production (Anthony et al., 2005; Cohen et al., 2017). 
The astrocytes are the major component of the brain tissue involved in the overall maintenance of brain homeostasis, neuronal metabolism and neuroprotection (Siracusa et al., 2019). However, active astrocyte dysfunction during hyperglycemia characterized by a decrease in glial fibrillary acidic protein (GFAP) level has been reported to promote neurocognitive dysfunctions (Coleman et al., 2004; Yang et al., 2018; Zhang et al., 2015).

The continuous use of HAART to prevent a viral rebound in people living with HIV and diabetesinduced neuroinflammation poses detrimental effects on astrocytes in the CNS, and this contributes significantly to the aetiology of neuro-pathologies (Cohen et al., 2017; Yang et al., 2018). Excessive production of pro-inflammatory cytokines during neuroinflammation have been implicated in cognitive deficits and anxiety disorders (Charlton et al., 2018; Li et al., 2019). Interestingly, in the post-era of HAART, people living with HIV have experienced an improvement in motor skills, verbal fluency, but executive functions and anxiety-like behaviour remain dominant impairments (Checa et al., 2020; Heaton et al., 2011). In addition, the prevalence of anxiety and depression among the patient receiving HAART remains high (Nuesch et al., 2009; Rabkin et al., 2000). The most used components of HAART (Efavirenz and Tenofovir) have been reported to cross the blood-brain barrier, causing mitochondrial dysfunction and some neurological-related adverse effects like depression and anxiety disorder (Checa et al., 2020; Chen et al., 2019). Several studies have suggested that the prefrontal cortex and its circuitry play a vital role in anxiety-like behaviour in animals and humans (Hare \& Duman, 2020; Likhtik et al., 2014). More so, a decrease in the prefrontal cortex activities and abnormalities in the neuroimaging studies have been observed in fearful and anxious individuals (Berkowitz et al., 2007; Likhtik et al., 2014). 
The application of nanomedicine for antiretroviral drugs delivery holds promise in HIV therapeutics due to their unique advantages such as increased bioavailability, stability and targeting cell population, as well as increasing the half-lives of drugs (Kumar et al., 2015).

The primary issue with HAART is that it requires high doses for a prolonged duration of time to reduce the viral level in the system, thus predispose living tissue to toxicity (Kumar, 2019). Silver nanoparticles (AgNPs) exhibit novel properties, which make them suitable for a wide range of applications in the biomedical field. In addition, AgNPs are the most-studied and utilized nanoparticles due to their simple method of synthesis, high surface to volume ratio, unique morphology and intracellular delivery system (Marin et al., 2015). In the biomedical field, AgNPs has been utilized as antiviral, antidiabetic and antioxidant agents (Vadlapudi \& Amanchy, 2017). Conversely, in vitro and in vivo studies on the neurotoxic effects of silver and silver nanoparticles reported a size- and dose-dependent cellular uptake and toxicity (Ferdous \& Nemmar, 2020; Greish et al., 2019a). Small-medium size nanoparticles have been reported less toxic to the cell (Lara et al., 2010). More so, studies have reported that cytotoxic effects of silver nanoparticles can be minimized by reducing silver ions to a ground state (from $\mathrm{Ag}^{+}$to $\mathrm{Ag}^{0}$ ), synthesizing a spherical shape, small-medium size, and modified surface area (Dlugosz et al., 2020; Smith et al., 2018). Another study suggests that the cytotoxic effect observed in the use of silver nanoparticles is due to silver ions exposure (Wang et al., 2014).

However, there is no data to substantiate the interaction of HAART loaded with silver nanoparticles on neuronal cells and neurocognitive dysfunctions. Hence, this study aims at assessing the role of HAART-silver nanoparticles conjugate on the PFC of fructose-STZ induced diabetic rats via oxidative stress, pro-inflammatory cytokines, and GFAP positive astrocyte. 


\section{Materials and methods}

\subsection{Materials}

The Atripla, a combined form of (Efavirenz (EFV, $600 \mathrm{mg}$ ), Emtricitabine (FTC, $200 \mathrm{mg}$ ) and Tenofovir disoproxil fumarate (TDF, $300 \mathrm{mg}$ ), was purchased from Dis-Chem pharmacy Ballito, South Africa. Streptozotocin (STZ), trisodium citrate, Sodium hydroxide and silver nitrate $\left(\mathrm{AgNO}_{3}\right)$ of analytical grade were sourced from Sigma-Aldrich Company, Johannesburg, South Africa. Enzyme-linked immunoassay (ELISA) kits TNF- $\alpha$ (E-EL-R0019) and interleukin (IL)-1 $\beta$ (E-EL-R0012) were purchased from BIOCOM Africa (pty), Ltd, South Africa. All the chemicals, reagents, and equipment were of analytical grade.

\subsection{Experimental animal}

Forty-two (42) adult male Sprague-Dawley rats (250 $\pm 13 \mathrm{~g})$ were obtained from the Biomedical Research Unit (BRU) of the University of KwaZulu-Natal and were housed in the standard animal laboratory room. The animal laboratory room was maintained at a temperature of $24-26{ }^{\circ} \mathrm{C}$ and 12:12 light: dark cycle, 40-60\% humidity. The animals were allowed free access to water and feed ad libitum. All animals were handled in accordance with standard guides for the animal laboratory, and the procedures were approved by the Animal Ethics Committee of the University of KwaZuluNatal (AREC/044/019D).

\subsection{Experimental design}

After acclimatization for six (6) days, the rats were randomly divided into six groups $(n=7)$ and were treated for eight weeks as follows: Drug dosage adopted was according to (Everson et al., 2018). 

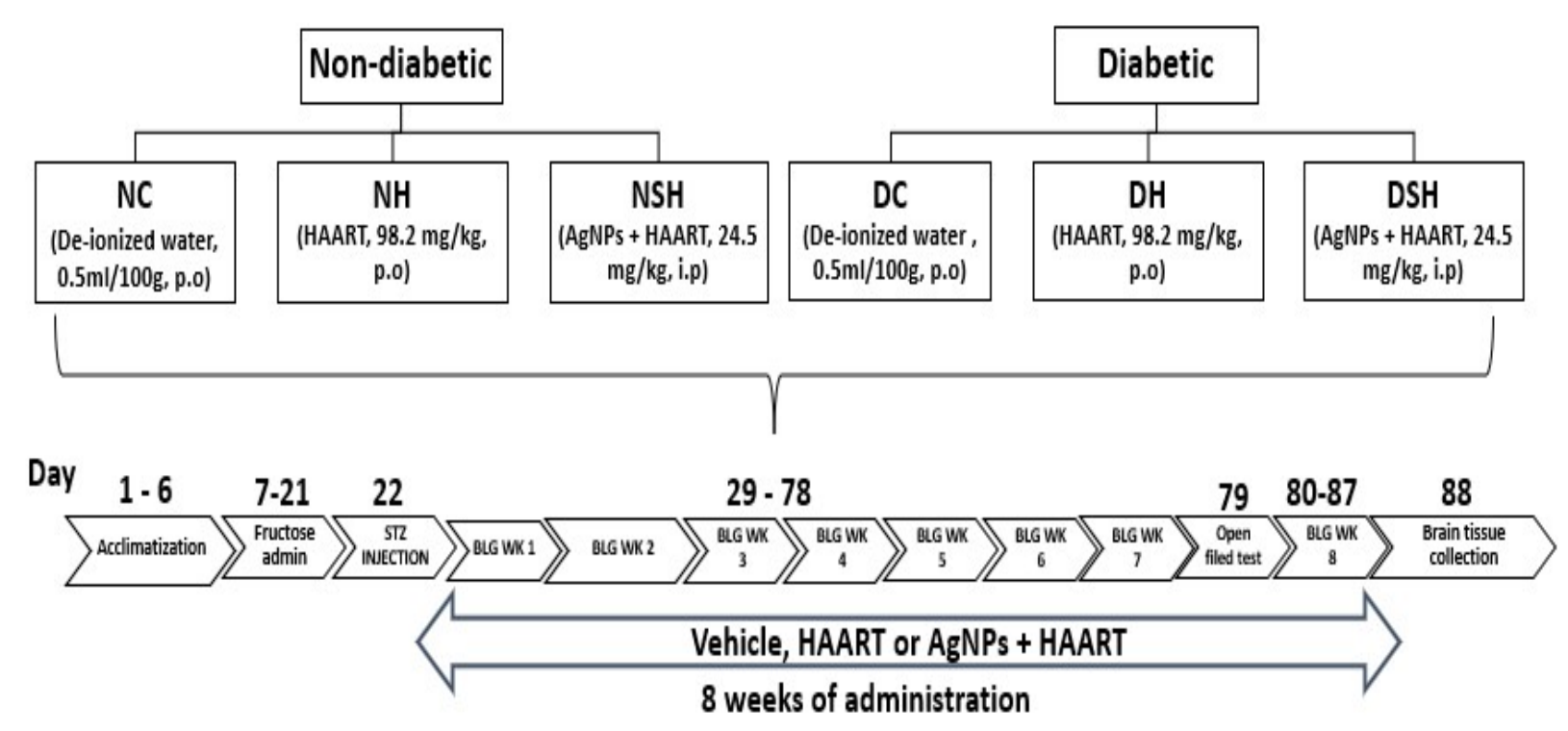

Figure 1. Illustrate experimental design. Group 1-3, designated as NC, NH and NSH were non-diabetic animals, but treated with vehicle (distilled water, $0.5 \mathrm{ml} / 100 \mathrm{~g}$, p.o), HAART (98.2 mg/kg, p.o), and AgNPs + HAART (24.5 mg/kg, i.p). Group 4-6, designated as DC, DH and DSH were diabetic animals treated with (distilled water, $0.5 \mathrm{ml} / 100 \mathrm{~g}$, $\mathrm{p}$. o), HAART (98.2 mg/kg, p. o), and AgNPs + HAART (24.5 mg/kg, i.p). All rats were treated daily except for i.p groups treated 5/7 days respectively for eight weeks. $\mathrm{NC}=$ non-diabetic control, $\mathrm{NH}=$ non-diabetic $+\mathrm{HAART}, \mathrm{NSH}=$ non-diabetic + AgNPs + HAART, $\mathrm{DC}=$ diabetic Control, $\mathrm{DH}=$ diabetic + HAART, $\mathrm{DSH}=$ diabetic + AgNPs + HAART, i. $\mathrm{p}=$ intraperitoneal injection. $\mathrm{p} . \mathrm{o}=$ per os, $\mathrm{BLG} \mathrm{WK}=$ blood glucose weekly measurement, $\mathrm{STZ}=$ streptozotocin.

\subsection{Induction of Type II Diabetes in rats}

Experimental type 2 diabetes mellitus was using fructose-Streptozotocin (STZ) rat model as described by (Wilson \& Islam, 2012). Briefly, rats received 10\% fructose solution ad libitum for two weeks. After that, the rats were fasted overnight and injected with a single of $40 \mathrm{mg} / \mathrm{Kg} \mathrm{B} . \mathrm{W}$ STZ i.p STZ dissolved in $0.9 \% \mathrm{NaCl}$ with $100 \mathrm{mM}$ sodium citrate buffer (pH 4.5). The control rats received an equal volume of citrate buffer. Animals with fasting blood glucose levels $\geq 200$ $\mathrm{mg} / \mathrm{dL}$ were considered diabetes and included in this study. 


\subsection{Formulation of AgNPs + HAART}

Silver nanoparticles were synthesized according to (Turkevich et al., 1951). Briefly, an aqueous solution $(0.03 \mathrm{M})$ of silver nitrate $\left(\mathrm{AgNO}_{3}\right)$ was prepared from $5.10 \mathrm{~g}$ of AgNO3 crystal, a stock aqueous solution (2 M) of trisodium citrate (TSC) was prepared from $147 \mathrm{~g}$ in $250 \mathrm{~mL}$ of doubledistilled water, and it was used as a reducing and stabilizing agent. Four TSC solutions with varying concentration $(0.5 \mathrm{M}, 1 \mathrm{M}, 1.5 \mathrm{M} \& 2 \mathrm{M})$ prepared to test the AgNO3 stability.

The HAART silver nanoparticle (AgNPs + HAART) was prepared by dissolving $15 \mathrm{~g}$ of HAART in $10 \mathrm{~mL}$ concentrated sodium hydroxide, and distilled water was added to make $50 \mathrm{~mL}$. The final concentration for this mixture was 1.0452 of HAART, and this mixture was stirred on ultrasonication to ensure proper reaction of HAART and AgNPs.

The AgNPs + HAART was centrifuged at $4,500 \mathrm{rpm}, 40{ }^{\circ} \mathrm{C}$, for 40 minutes to discrete the unincorporated drug. The supernatant was analyzed using a UV spectrophotometer at a wavelength of 285-315 nm to calculate the quantity of unincorporated drug (W1) from the total amount of drug coupled with silver nanoparticle (W2).

The AgNPs + HAART percentage incorporated efficiency was calculated according to (Govender et al., 2006) as follows: $\% I E=\frac{W_{2}-W_{1}}{W_{1}} \times 100=90.52 \pm 0.5 \%$.

\subsection{Characterization of AgNPs and HAART-AgNPs}

The characterization of AgNPs and AgNPs + HAART was done to select the appropriate TSC concentration based on the nanoparticles size, shape, and morphology of the conjugates. Fourier transform infrared (FTIR) spectroscopy (Perkin-Elmer Universal ATR spectrometer, USA) was used to identify the various functional groups in the HAART-AgNPs conjugates. The HAART and AgNPs show absorption bands at $3303.13 \mathrm{~cm}^{-1}$ and 3227.27 respectively in the FTIR spectrum. 
The ultraviolet-visible (UV-Vis) spectroscopy (Shimadzu MultSpec-1501, Shimadzu Corporation, Tokyo, Japan) indicates that HAART-AgNPs synthesized with 1.5M AgNPs possess a significant smaller nanoparticle than the other concentration.

The size and morphology of the nanoparticles were examined by a high-resolution transmission electron microscope (HR-TEM, JEOL 2100, Japan) operated at a voltage of $200 \mathrm{kV}$. The nanoparticles (NPs) size for 1.5 concentration was $30-50 \mathrm{~nm}$, while morphology was spherical.

The field emission scanning electron microscope (FESEM, Carl Zeiss, Germany) operated at a voltage of $5 \mathrm{kV}$ with energy dispersive X-ray (EDX, Aztec Analysis Software, England).

Energy Dispersive X-ray (EDX) was used to determine the elemental components. The presence of silver, sodium and some functional groups indicated the silver nanoparticles were successfully incorporated with HAART.

\subsection{Blood glucose level and metabolic activities}

The weekly fasting blood glucose was determined using a portable glucometer (Sigma-Aldrich, Durban, South Africa), and the blood sample was obtained through the tail vein. The metabolic activities (calorie intake, water intake, urine volume and the number of faecal pellets) were monitored in individual rats using a novel metabolic cage.

\subsection{Behavioural assessment}

\subsubsection{Open field test (OFT) to measure the anxiety and explorative behaviours}

On day 79 of the experiment, the animals were evaluated for spontaneous and anxiety-like behaviours using the open field test. The open field apparatus consists of a large rectangular box measuring $70 \mathrm{~cm}$ long $\times 70 \mathrm{~cm}$ wide $\times 35 \mathrm{~cm}$ high with several $15 \mathrm{~cm} \times 15 \mathrm{~cm}$ squares. Animals were placed in the centre of the squares and were monitored for 5 minutes. The parameters for locomotion and anxiety-like behavioural activities (Total lines cross, peripheral line cross, centre 
lines cross, latency to leave the center square, centre square entries, frequency of urination and defecation) were measured and recorded (Bădescu et al., 2016; Eilam, 2003).

\subsection{Neurochemical analysis}

\subsubsection{Preparation of brain homogenates}

After the eight-week of treatment, all animals were euthanized by decapitation, the brains were harvested and immediately rinsed in cold phosphate-buffered saline (PBS), $0.5 \mathrm{~g}$ of the prefrontal cortex $(n=7)$ was dissected on the ice tray, thawed, and homogenized in $10 \%$ phosphate buffer (0.1M, pH 7.5). The homogenates were centrifuged for 10 mins at 20,000g $\left(4^{\circ} \mathrm{C}\right)$, and the supernatants were obtained for neurochemical analyses.

\subsubsection{Determination of superoxide dismutase (SOD), catalase (CAT) and malondialdehyde (MDA), and reduced glutathione level (GSH)}

Prefrontal cortex tissue homogenates were used to measure the concentration of reduced glutathione (GSH), superoxide dismutase (SOD), catalase (CAT) and malondialdehyde (MDA) by spectrophotometric assay. Reduced glutathione (GSH) level was assessed using the method of Ellman (1959) protocol. The antioxidant enzymes, superoxide dismutase (SOD) activity and catalase (CAT) were determined according to Kakkar et al. and Aebi 1984 respectively (Aebi, 1974; Kakkar et al., 1984), and malondialdehyde (MDA) level was determined by measuring the content of thiobarbituric acid (TBA) reactive products using the method of Mkhwanazi et al. (Mkhwanazi et al., 2014).

\subsubsection{Analysis of inflammatory biomarkers}

The concentration of cytokine-tumour necrosis factor- $\alpha$ (TNF- $\alpha$ ) and interleukin (IL)-1 $\beta$ were quantified in the prefrontal cortex homogenates using their specific ELISA kits (Elabscience Biotechnology Co., Ltd., Houston, TX, USA) according to the manufacturer's instructions. 


\subsubsection{Brain Tissue processing for microscopic study}

The prefrontal cortex $(n=2)$ was carefully removed and weighed, then post-fixed in $10 \%$ neutral buffer formalin (NBF) for 1 hour, then transferred to $15 \%$ sucrose in phosphate-buffered saline (PBS) until they sunk (24 hours). Afterwards, the tissue was transferred to $30 \%$ sucrose in PBS until they sunk and finally fixed in 10\% NBF for histology and immunochemistry through paraffin embedding. The tissues were sectioned at $5 \mu \mathrm{m}$ using Leica RM 2255 microtome, cleared in xylene, hydrated in decreasing alcohols, followed by Haematoxylin and Eosin (H\&E) and then mounted with DPX (Djidja et al., 2017).

\subsubsection{Immunohistochemical (IHC) analysis}

The uniform random sampling of the prefrontal cortex was used for the primary antibody (antiGFAP). The sections from the prefrontal cortex were washed in PBS $(2 \times 10 \mathrm{~min})$ at $4{ }^{\circ} \mathrm{C}$ and preincubated in $0.1 \mathrm{M}$ PBS, 5\% normal goat serum with $0.4 \%$ Triton X-100 and $1 \%$ bovine albumin serum for one hour at $4^{\circ} \mathrm{C}$ and then directly incubated in the primary antibody diluted in the phosphate-buffered saline (PBSA)-Triton (PBSAT: PBS 0.01 M, PH 7.4, 0.1\% of Sodium Azide and $0.3 \%$ Triton X 100) and prepared for 72 hours at $4{ }^{\circ} \mathrm{C}$ and under agitation. After PBST washes

( $2 \times 10 \mathrm{~min})$, sections were incubated in $0.1 \mathrm{M}$ PBS containing $2 \%$ normal goat serum and biotinylated rabbit anti-goat IgG (Secondary antibody) (1:2000) for 2 hours at room temperature, then rinsed in PBST $(2 \times 10 \mathrm{~min})$ and incubated with the avidin-biotin complex (AB; 1:2000) for 2 hours at room followed by several washes $(1 \times 10 \mathrm{~min}$ in PBST and $2 \times 10 \mathrm{~min}$ in Tris buffer (0.05 M, PH 7.6)). The peroxidase activity detection was carried out with 3-3' diaminobenzidine (DAB, $0.025 \%), 0.5 \%$ Nickel ammonium sulphate in tris buffer $(0.1 \mathrm{M}, \mathrm{pH} 7.6)$ with $0.03 \%$ hydrogen peroxide. The immunoreactive reaction was stopped by washing the sections once in 0.1 M Tris buffer (10 min) and twice in 0.1 M PBS (10 min). Sections were dehydrated in progressive 
ethanol baths, cleared in 2 successive xylene baths, and mounted onto gelatine-coated slides and coverslipped with Eukitt.

\subsubsection{Quantification of immunostained astrocytes}

Immunostained astrocytes counting was conducted under an optical microscope (Olympus BH2) connected via a CCD high-performance camera (COHU) to the Scion Image stereological software (Scion Corporation, version Beta 4.0.2) equipped computer. The counting was made in 6 sections per animal along with the rostrocaudal plan for each structure. The overall immunoreactivity was calculated for each structure. The results were represented as mean \pm standard error mean (SEM).

\subsection{Statistical Analysis}

Data were presented as mean \pm SEM and analyzed. The differences between means were compared using one-way analysis (ANOVA), followed by Tukey's multiple comparison test to determine the statistical significance between the groups. All analyses were done using GraphPad Prism 8 for Windows (GraphPad Software San Diego, CA 92108). P <0.05 was considered statistically significant. 


\section{Results}

\subsection{AgNPs + HAART reduces blood glucose level in diabetic rats}

The effect of HAART and AgNPs + HAART on blood glucose levels in non-diabetic and diabetic rats (Figure 2). Blood glucose levels increased significantly in all the diabetic groups (DC, DH and DSH) one week post-STZ vs non-diabetic group (NC). Diabetic rats administered HAART (group DH) had a significant increase $(\mathrm{p}<0.05)$ blood glucose level compared with diabetic control. While rats administered AgNPs + HAART (group DSH) had a substantial decrease in blood glucose after eight weeks of treatment vs diabetic control (DC) and diabetic treated rats only (group DH). Conversely, there was no significant difference in blood glucose levels in the non-diabetic groups.

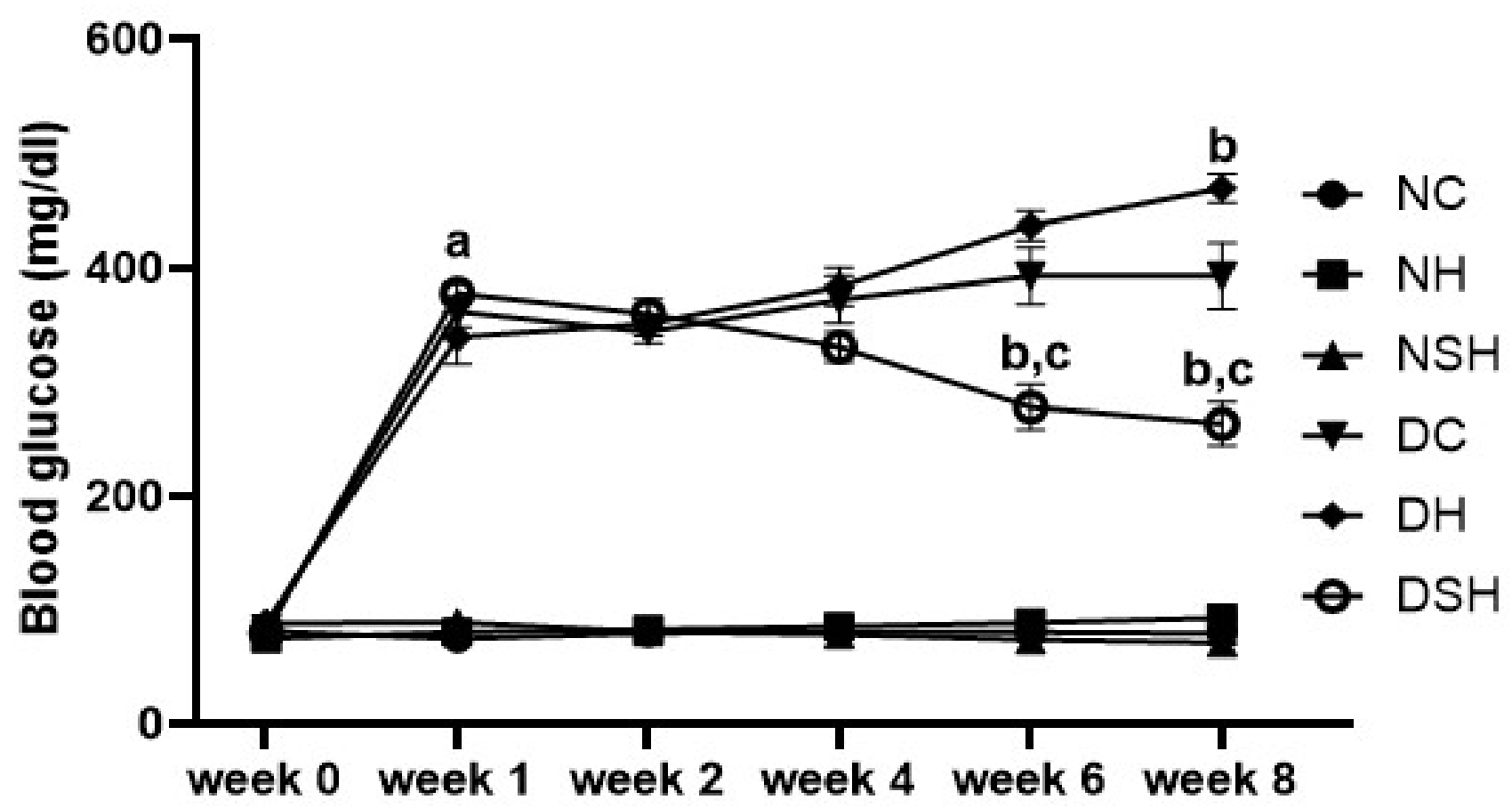

Figure 2: Illustrate the weekly changes in blood glucose level in non-diabetic and diabetic rats treated with either vehicle, HAART, or AgNPs + HAART. $\mathrm{NC}=$ nondiabetic control, NH=non-diabetic $+\mathrm{HAART}, \mathrm{NSH}=$ non-diabetic + silver nanoparticles + HAART, $\mathrm{DC}=$ diabetic control, $\mathrm{DH}=$ diabetic + HAART, $\mathrm{DSH}=$ diabetic + silver nanoparticles + HAART. ${ }^{a}$ vs NC; ${ }^{b} \mathrm{p}<0.05$ v DC, ${ }^{c} \mathrm{p}<0.05 \mathrm{v} \mathrm{DH},(\mathrm{n}=7)$. 


\subsection{AgNPs + HAART improves metabolic activities and anxiety-like behaviour}

The effects of HAART and AgNPs + HAART on metabolic activities and anxiety-like behaviour in non-diabetic and diabetic rats (Table 1). The metabolic biomarkers were significantly (water intake and urine volume $\mathrm{p}<0.05$ ); (food consumption and faecal pellets $\mathrm{p}<0.0001$ ) increased in the diabetic control group (DC) compared to non-diabetic control (NC). The water intake and faecal pellets were significantly increased in group DH (diabetic plus HAART) $(72.13 \pm 1.394)$ compared with diabetic control DC (62.25 \pm 1.88$)$. Interestingly, both water intake and faecal pellets were significantly decreased in group DSH (diabetic + AgNPs +HAART) (48.13 \pm 2.10$)$ compared to $\mathrm{DH}(72.13 \pm 1.394)$.

\begin{tabular}{lllll}
\hline \multicolumn{5}{c}{ Metabolic activity parameter } \\
\cline { 1 - 2 } & Water intake $\left(\mathrm{cm}^{3}\right)$ & Urine Volume $\left(\mathrm{cm}^{3}\right)$ & Food intake $(\mathrm{mg})$ & Faecal pellets \\
\hline ND & $36.388 \pm 0.53$ & $19.75 \pm 0.25$ & $21.69 \pm 1.23$ & $17.38 \pm 1.22$ \\
NH & $39.13 \pm 0.22$ & $20.63 \pm 1.19$ & $23.78 \pm 0.88$ & $20.00 \pm 1.19$ \\
NSH & $36.63 \pm 1.15$ & $20.75 \pm 0.31$ & $22.96 \pm 1.61$ & $16.63 \pm 1.32$ \\
DC & $62.25 \pm 1.88^{\text {aa }}$ & $47.00 \pm 3.09^{\text {aa }}$ & $34.63 \pm 1.99^{\mathbf{a}}$ & $24.38 \pm 1.10^{\mathbf{a}}$ \\
DH & $72.13 \pm 1.394^{\mathbf{b}}$ & $58.50 \pm 2.19$ & $41.30 \pm 2.47$ & $32.25 \pm 2.23^{\mathbf{b}}$ \\
DSH & $48.13 \pm 2.10^{\mathbf{c}}$ & $39.25 \pm 3.69$ & $34.85 \pm 1.72$ & $20.38 \pm 1.45^{\mathbf{c}}$ \\
\hline
\end{tabular}

Table 1: Effect of AgNPs + HAART on metabolic activities (water intake, urine volume, food intake, and faecal pellet number) in diabetic rats. ${ }^{a} \mathrm{p}<0.05,{ }^{\mathrm{aa}} \mathrm{p}<0.0001 \mathrm{vs} \mathrm{NC},{ }^{\mathrm{b}} \mathrm{p}<0.05 \mathrm{v} \mathrm{DC},{ }^{\mathrm{c}} \mathrm{p}<0.05 \mathrm{v} \mathrm{DH}$. NC=nondiabetic control, $\mathrm{NH}=$ non-diabetic $+\mathrm{HAART}, \mathrm{NSH}=$ non-diabetic + silver nanoparticles $+\mathrm{HAART}, \mathrm{DC}=$ diabetic control, $\mathrm{DH}=$ diabetic + HAART, DSH= diabetic + silver nanoparticles+ HAART, $(\mathrm{n}=7)$. 


\subsection{The AgNPs + HAART mitigates anxiety-like behaviours in the open field test}

The effects of HAART and AgNPs + HAART on anxiety-like behaviours in non-diabetic and diabetic rats (Figure 3 ). There was a significant reduction $(\mathrm{p}<0.05)$ in latency to leave the centre and centre square entries of group DC compared to group NC. Group DH (diabetic +HAART) significantly reduced latency and centre square entries compared to group DC. Notable, group DSH showed a significant $(\mathrm{p}<0.05)$ increase $(9.375 \pm 0.596)$ in latency compared to group DH (6.625 \pm 0.3750$)$. The centre square entries were significantly in group DSH (AgNPs + HAART)

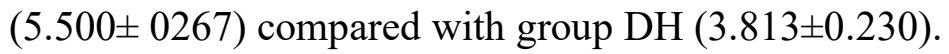
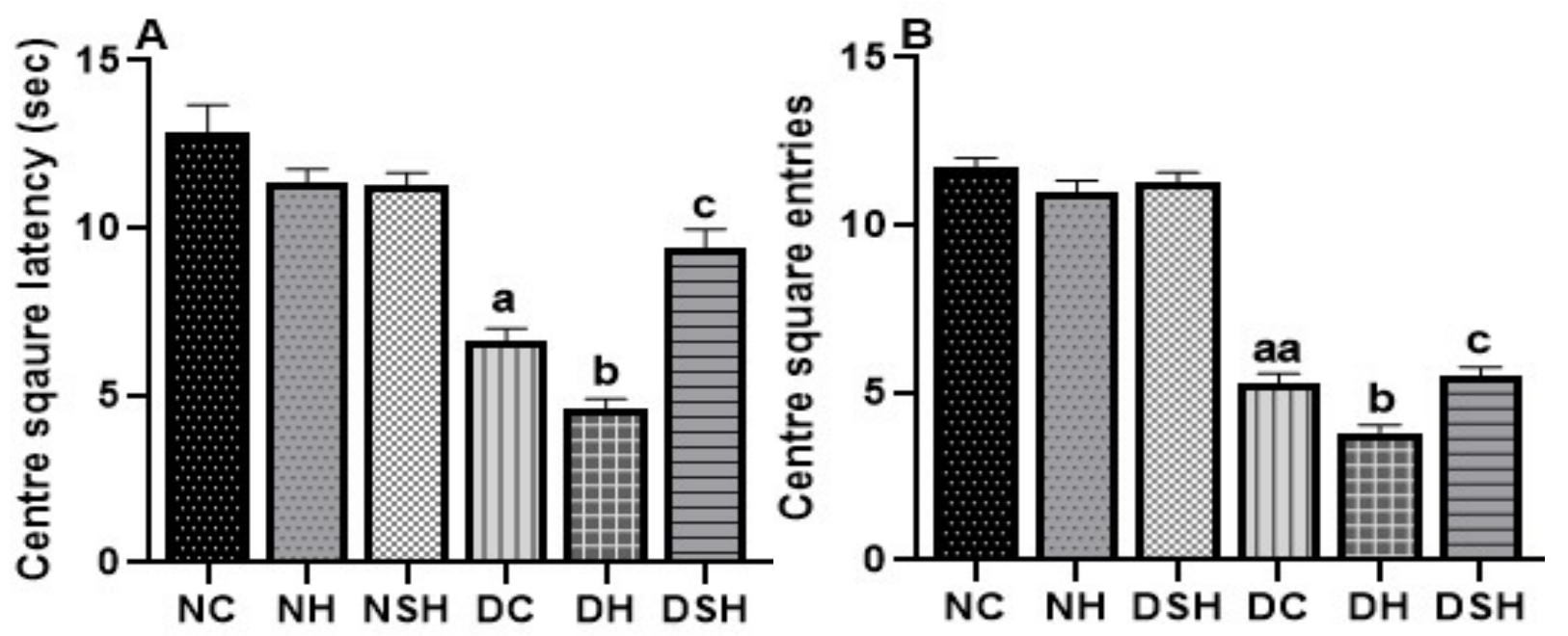

Figure 3: Effect of AgNPs + HAART on Anxiety-like behaviour in diabetic rats. ${ }^{a} \mathrm{p}<0.05$, ${ }^{a a} \mathrm{p}<0.0001$ vs vs NC, ${ }^{\mathrm{b}} \mathrm{p}$ $<0.05 \mathrm{v}$ DC, ${ }^{\mathrm{c}} \mathrm{p}<0.05 \mathrm{v}$ DH. $\mathrm{NC}=$ nondiabetic control, $\mathrm{NH}=$ non-diabetic + HAART, NSH=non-diabetic + silver nanoparticles + HAART, $\mathrm{DC}=$ diabetic control, $\mathrm{DH}=$ diabetic + HAART, DSH= diabetic + silver nanoparticles + HAART. $A=$ center square latency, $B=$ center square entries, $(n=7)$.

\subsection{AgNPs + HAART increases locomotion activities}

The effects of HAART and AgNPs + HAART on locomotion activities in non-diabetic and diabetic rats (Figure 4). All indices of locomotion activities were significantly $(\mathrm{p}<0.05)$ reduced 
in the DC group compared to group NC. The diabetic rats administered HAART (group DH)

showed a significant $(\mathrm{p}<0.05)$ reduction in locomotion compared to group DC and group DSH.

Interestingly, there was a significant increase in centre line cross in rats administered with AgNPs

+ HAART (group DSH) compared with group DH.
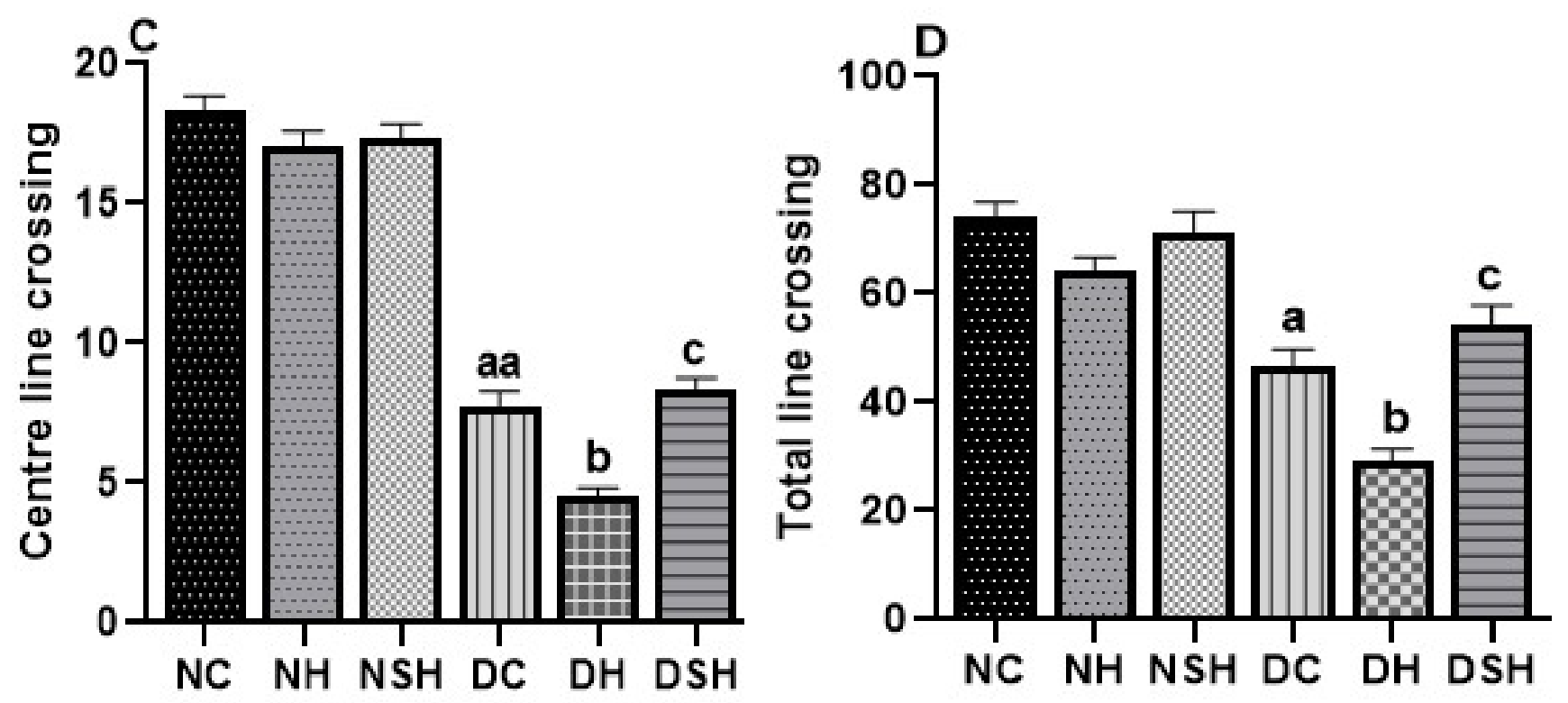

Figure 4: Effect of AgNPs + HAART on locomotion in diabetic rats. ${ }^{\mathrm{a}} \mathrm{p}<0.05,{ }^{\mathrm{aa}} \mathrm{p}<0.0001 \mathrm{vs} \mathrm{NC},{ }^{\mathrm{b}} \mathrm{p}<0.05 \mathrm{v} \mathrm{DC}$, ${ }^{\mathrm{c}} \mathrm{p}<0.05 \mathrm{v}$ DH. $\mathrm{NC}=$ nondiabetic control, $\mathrm{NH}=$ non-diabetic + HAART, NSH=non-diabetic + silver nanoparticles + HAART, DC= diabetic control, $\mathrm{DH}=$ diabetic $+\mathrm{HAART}, \mathrm{DSH}=$ diabetic + silver nanoparticles $+\mathrm{HAART} . \mathrm{A}=\mathrm{Centre}$ line crossing, $B=$ total line cross, $(n=7)$.

\subsection{AgNPs + HAART reduces prefrontal cortex inflammatory biomarkers (TNF- $\alpha$ and IL-} 1及)

The effects of HAART and AgNPs + HAART on inflammatory markers in non-diabetic and diabetic rats (figure 5a-b). The concentration of inflammatory biomarkers (TNF- $\alpha$ and IL-1 $\beta$ ) were significantly $(\mathrm{p}<0.05)$ increased in the DC group compared to the NC group. The diabetic rat administered HAART (group DH) showed a significant $(\mathrm{p}<0.05$ ) increase in both TNF- $\alpha$ and IL- 
$1 \beta$ compared to the DC rat. However, the diabetic rat administered AgNPs + HAART (group DSH) showed a reduction in inflammatory biomarkers compared with HAART only but not significant.
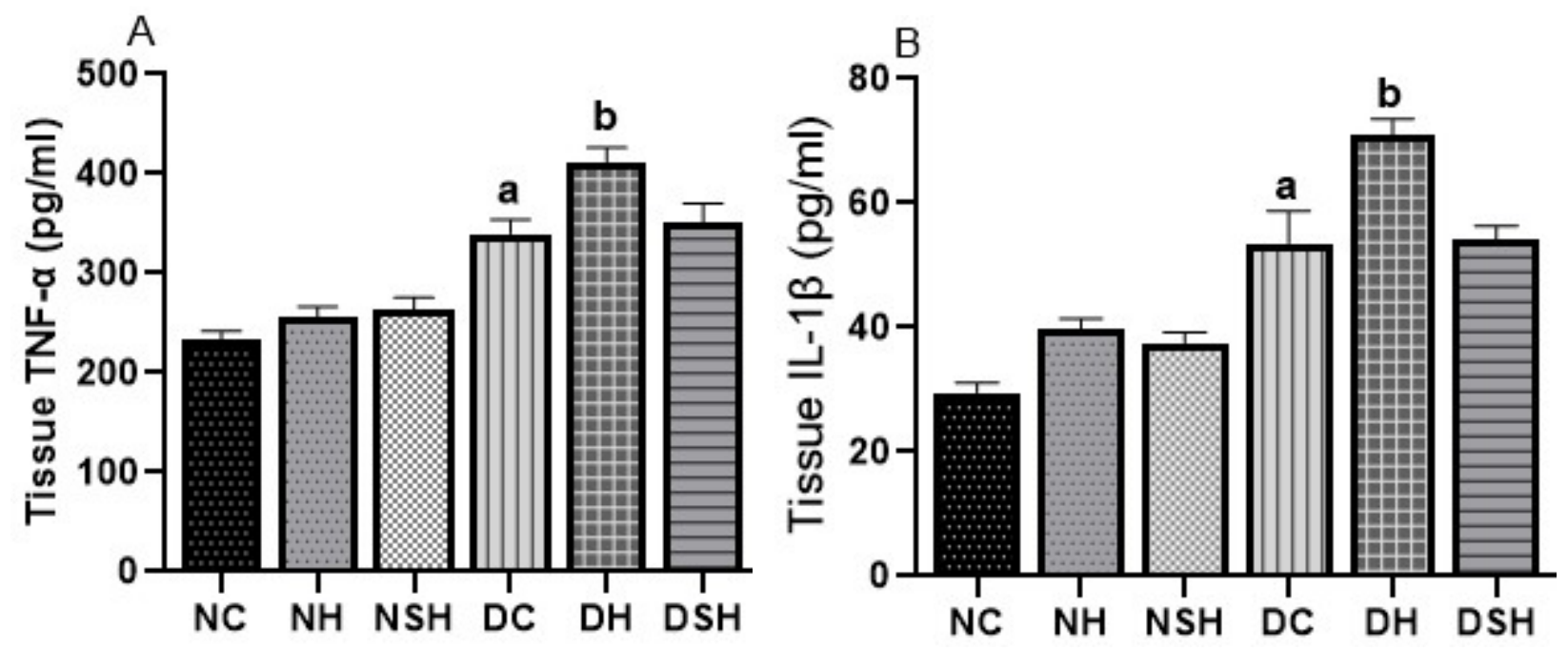

Figure 5: Effect of AgNPs + HAART on inflammatory response in the Prefrontal cortex of diabetic rats. ${ }^{a} \mathrm{p}<0.05$ vs $\mathrm{NC},{ }^{\mathrm{b}} \mathrm{p}<0.05 \mathrm{v} \mathrm{DC} . \mathrm{NC}=$ nondiabetic control, $\mathrm{NH}=$ non-diabetic $+\mathrm{HAART}, \mathrm{NSH}=$ non-diabetic + silver nanoparticles + HAART, DC $=$ diabetic control, DH=diabetic + HAART, DSH= diabetic + silver nanoparticles + HAART. TNF- $\alpha=$ tumour necrosis factor- alpha, IL-1 $1 \beta$ = interleukin-1 beta, $A=T N F-\alpha, B=I L-1 \beta,(n=7)$.

\subsection{AgNPs + HAART enhances antioxidant enzymes activities}

The effect of HAART and AgNPs + HAART on oxidative stress biomarkers (Fig 6 a-d). The diabetic control group had a significant $(\mathrm{p}<0.05)$ increase in MDA level and a significant $(\mathrm{p}<$ 0.05) decrease in catalase, SOD and GSH compared with the non-diabetic control group.

Administration of HAART to the diabetic rat (DH) significantly increased MDA with a reduction in SOD and GSH compared to diabetic control. However, administration of AgNPs + HAART to diabetic animals (DSH) caused a significant decrease in MDA level and increased GSH and SOD levels compared with group DH $(\mathrm{p}<0.05)$. 

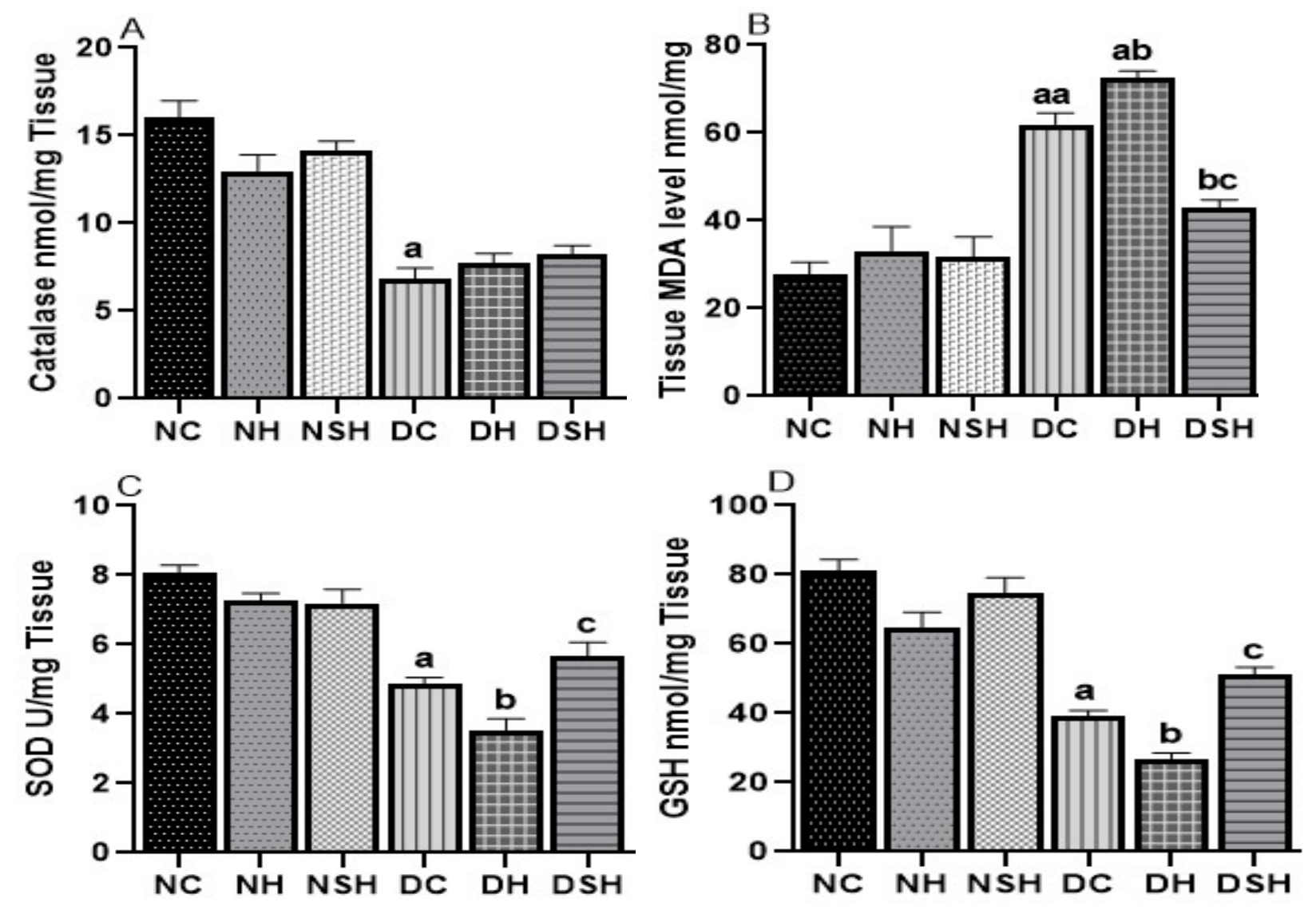

Figure 6: Effect of HAART on oxidative stress in the Prefrontal cortex of diabetic rats. ${ }^{\mathrm{a}} \mathrm{p}<0.05 \mathrm{vs} \mathrm{NC},{ }^{\mathrm{b}} \mathrm{p}<0.05 \mathrm{v}$ $\mathrm{DC},{ }^{\mathrm{c}} \mathrm{p}<0.05 \mathrm{v} \mathrm{DH} . \mathrm{NC}=$ nondiabetic control, $\mathrm{NH}=$ non-diabetic $+\mathrm{HAART}, \mathrm{NSH}=$ non-diabetic + silver nanoparticles + HAART, $\mathrm{DC}=$ diabetic control, $\mathrm{DH}=$ diabetic + HAART, $\mathrm{DSH}=$ diabetic + silver nanoparticles + HAART. A= Catalase, $B=$ Malondialdehyde, $\mathrm{C}=$ superoxide dismutase $(\mathrm{SOD}), \mathrm{D}=$ reduced glutathione $(\mathrm{GSH}),(\mathrm{n}=7)$.

\subsection{AgNPs + HAART protects GFAP positive astrocytes in the prefrontal cortex}

The effect of HAART and AgNPs + HAART on GFAP positive astrocytes (Figure 7). There was a significant reduction in GFAP positive astrocytes in the prefrontal cortex of diabetic control (DC) compared to non-diabetic control (NC). Administration of HAART to diabetic rats (DH) caused a significant reduction in GFAP positive astrocytes compared with group DC. Administration of AgNPs + HAART to diabetic rats (DSH) significantly increased GFAP positive astrocytes compared to group DH. 

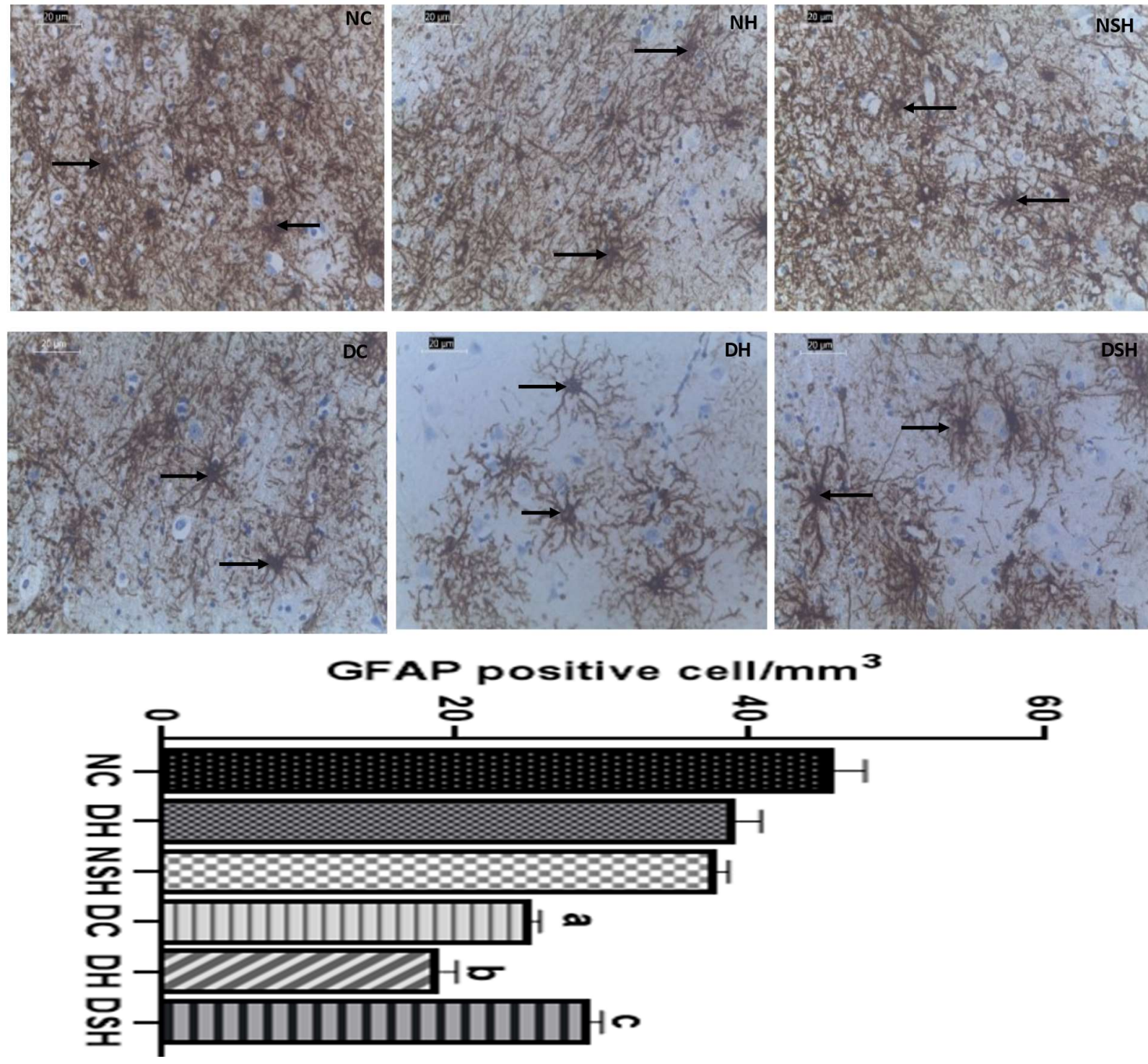

Figure 7: Effect of AgNPs + HAART on GFAP positive astrocytes in the Prefrontal cortex. NC= nondiabetic control, $\mathrm{NH}=$ non-diabetic $+\mathrm{HAART}, \mathrm{NSH}=$ non-diabetic + silver nanoparticles $+\mathrm{HAART}, \mathrm{DC}=$ diabetic control, $\mathrm{DH}=$ diabetic + HAART, DSH= diabetic +silver nanoparticles + HAART, GFAP $=$ glial fibrillary acidic protein. ${ }^{a} \mathrm{p}<0.05 \mathrm{v}$ NC, ${ }^{b} \mathrm{p}$ $<0.05 \mathrm{v}$ DC, ${ }^{\mathrm{c}} \mathrm{p}<0.05 \mathrm{v}$ DH. Black arrow indicates immunostained astrocytes, $(\mathrm{n}=2)$.

\section{Discussion}

In this study, the prefrontal cortex (PFC), being the centre for coordinating, adjusting several complex behaviours and controlling anxiety-like behaviour and emotion, was studied to determine the potential benefits of silver nanoparticles on the anxiogenic effects of HAART in diabetic rats. 
More so, PFC pathways regulate anxiety processing and autonomic drive through their interconnectivity with cortical regions (Kenwood et al., 2021).

HAART is required at higher doses for a lifetime to maintain an undetectable viral load in people living with HIV, which predisposes them to systemic toxicity and metabolic disorders such as diabetes mellitus. More so, silver nanoparticles are used for a wide range of applications in the biomedical field, such as antiviral, antioxidant and antidiabetic agents due to their unique properties and ability to reduce chronic effects of these agents (Vadlapudi \& Amanchy, 2017). Therefore, we hypothesized that HAART loaded silver nanoparticles may exert a beneficial effect by reducing the dosage of HAART and its neurotoxic effect while improving the neurological disorders caused by HAART.

In this study, the diabetic rats treated with HAART had persistently increased blood glucose levels across the weeks. This result showed that the chronic administration of HAART contributed to the hyperglycaemic effect of diabetes. The development of hyperglycaemia has been reported with the prolonged use of HAART in people living with HIV (Sharma, 2014). The cause of the hyperglycaemic effect of HAART has been attributed to insulin resistance and mitochondrial dysfunction, and metabolic disorders (Avari \& Devendra, 2017).

Conversely, the reduced blood glucose in rats treated with HAART loaded with silver nanoparticles (AgNPs + HAART) may be attributed to the potential of silver nanoparticles to increase insulin secretion, thereby promoting glucose uptake. A similar study has shown the antidiabetic activity of silver nanoparticles via up-regulation of insulin receptors and higher expression of glucokinase genes (Alkaladi et al., 2014). Furthermore, this may result from the reduced dosage of HAART in the AgNPs + HAART synthesis, which could alleviate the effects of chronic administration of HAART (Iravani et al., 2014). 
The metabolic disturbances of HAART were observed as evidenced in increased defecation and water intake of diabetic rats. Literature has shown that an increase in defecation is a valuable indicator for anxiety-like behaviours and is frequently observed in highly emotional animals (Crumeyrolle-Arias et al., 2014; Hall, 1934).

The administration of HAART to the diabetic rats exacerbates anxiety-like behaviour compared to diabetic control and diabetic rats treated with HAART plus silver nanoparticles. Evidence of behavioural deficits and anxiogenic effects of HAART was seen in the open field test. The centre square entries, the latency to leave the centre square, and the centre line cross corresponded with the total line cross were significantly reduced in the diabetic HAART-treated group. The nonnucleoside reverse transcriptase inhibitors (NNRTIs) and nucleoside reverse transcriptase inhibitors (NRTI) acts as the backbones of HAART and are effective in controlling the viral load. Still, despite this, these HAART components are associated with neuropsychological disturbances, fatigue, and dizziness (Romao et al., 2011). More so, chronic treatment of Efavirenz (NNRTIs) has been reported to induce an anxiety-like effect in the mice (Romao et al., 2011). In addition, reports have indicated that $50 \%$ of patients treated with efavirenz experience central nervous system (CNS) disturbances and psychiatric effects such as anxiety, depression, and suicidal ideation (Cavalcante et al., 2017; Raines et al., 2005).

This study observed a significant increase in the prefrontal cortex MDA level of diabetic-HAART treated rats. This may be due to excessive production of ROS, which occurs during the intracellular phosphorylation of NRTIs in the prefrontal cortex. The excessive ROS production and the reduced antioxidant enzymes CAT, SOD and GSH, lead to the induction of oxidative stress. The ensuing oxidative injury promotes lipid peroxidation that compromises mitochondrial biogenesis, which has been implicated in HAART-induced mitochondrial dysfunction (Schank et al., 2021). In 
addition, the inner mitochondrial membrane is permeable to small neutral molecules, thereby hindering exogenous antioxidants from reaching the mitochondrial (Kirkinezos et al., 2005). Previous studies have also shown that neuropathy observed in HIV patients receiving HAART and diabetic neuropathic complications could be due to increased ROS production that promotes cellular toxicity and neuroinflammation (Nsonwu-Anyanwu et al., 2017; Pang et al., 2020; Sharma, 2014).

Increased oxidative stress triggers the release of pro-inflammatory cytokines (TNF- $\alpha$ and IL-1 $\beta$ ) reported in the PFC of HAART-treated and diabetic control rats, which may account for the neuronal injury observed in this study. The brain tissues are particularly susceptible to oxidative stress and neuronal damage due to their low antioxidant defense system, high amount of unsaturated fatty acid, and high oxygen consumption (Salim, 2017). An increase in the concentration of pro-inflammatory cytokines (TNF- $\alpha$ and IL-1 $\beta$ ), as well as inhibition of antioxidants enzymes (CAT, SOD) and GSH, exacerbated anxiety-like behaviour in diabetic rats treated with HAART. A similar report has established an increase in TNF- $\alpha$ and IL-1 $\beta$ in mood and anxiety disorders (Quagliato \& Nardi, 2018).

Several studies have confirmed the role of PFC in anxiety disorders (Hare \& Duman, 2020; Tovote et al., 2015). HAART caused astrocyte dysfunction in the diabetic rats via a significant decrease in PFC-GFAP positive cell number. This loss of astrocytic functions may contribute to the anxiogenic effects of HAART. Astrocytes are the most abundant neuroglial and are involved in many brains functions, particularly mood disorders and anxiety-like behaviours (Sofroniew \& Vinters, 2010). Reduction in oxidative stress and neuroinflammation caused by HAART and diabetes may be achieved by incorporating silver nanoparticles into HAART. 
Silver nanoparticles offer an advantage as delivery vehicles in many therapeutic agents. More so, silver nanoparticles are known for their antioxidant and antidiabetic properties (Vadlapudi \& Amanchy, 2017).

In this study, incorporating HAART with silver nanoparticles alleviates the anxiety-like behaviours in the diabetic HAART-treated rats via a reduction in MDA and improvement in GSH, CAT and SOD. This suggests that silver nanoparticles may reduce the oxidative damage caused by the excessive production of ROS during the intracellular phosphorylation of HAART in the PFC. This result agrees with a previous finding that reported a higher antioxidant activity of silver nanoparticles compared with vitamin C in cell culture (Keshari et al., 2020).

Furthermore, a significant increase in the PFC-GFAP positive cell count was observed in AgNPs + HAART treated animals. This may be attributed to the antioxidant properties of silver nanoparticles to delay or prevent the loss of astrocytes in the PFC because studies have shown the therapeutic potential of silver nanoparticles in tissue restoration and regeneration (Burdusel et al., 2018).

Notably, there was no significant change in the PFC concentration of pro-inflammatory cytokines (TNF- $\alpha$ and IL-1 $\beta$ ) of AgNPs + HAART treated rats compared with diabetic control. This result suggests that silver nanoparticles may mitigate the neurotoxic effect of diabetes and may have neuroprotective functions against the adverse effect of HAART. But further studies are needed to reveal the exact mechanism by which AgNPs + HAART induce the improvement of HAART via anti-inflammatory pathways.

Although, some studies have reported the mild neurotoxic effects of silver nanoparticles (Greish et al., 2019b; Wesierska et al., 2018). However, the advantages of using silver nanoparticles as a vehicle in delivering therapeutic agents may outweigh the adverse effects due to their unique 
physicochemical characteristics, antioxidant, and anti-inflammatory properties. More so, the neurotoxic effects of silver nanoparticles depend on various factors, particularly the synthesis method (Alkaladi et al., 2014; Seethalakshmi 2015).

In addition, the reduction of $\mathrm{Ag}^{+}$to $\mathrm{Ag}^{0}$ using a concentration of $1.5 \mathrm{M}$ trisodium citrate (TSC) as a reducing and stabilizing agent with a nanoparticle size between 19-35 $\mathrm{nm}$ and spherical morphology may be an essential factor in the silver nanoparticles synthesis and their effect on the PFC. These results were supported by the previous investigation of silver nanoparticles synthesis where the silver ion has been reduced to a ground state from $\mathrm{Ag}^{+}$to $\mathrm{Ag}^{0}$, and synthesized nanoparticles were within the small-medium nano-sized particle (20-50 nm) (Iravani et al., 2014; Lara et al., 2010; Van Dong et al., 2012). More so, a study has reported that the cytotoxic effect observed in the use of silver nanoparticles is due to silver ions exposure (Wang et al., 2014).

\subsection{Conclusion}

In this study, the administration of HAART aggravates anxiety-like behaviours and promotes neurotoxic effects on the PFC of diabetic rats. However, HAART conjugated with silver nanoparticles mitigate the anxiogenic effects of HAART and preserves PFC-GFAP positive cells by reducing oxidative injury and inflammatory damage.

\section{Ethics approval:}

All animals were handled in accordance with standard guides for the animal laboratory, and the procedures were approved by the Animal Ethics Committee of the University of KwaZulu-Natal (AREC/044/019D).

\section{Consent for publication}

All authors have read and accepted responsibility for the content of the manuscript. 


\section{Funding}

This work was supported by the College of Health Sciences, University of KwaZulu-Natal (grant number 640967).

\section{Conflict of interest disclosure:}

The authors have no conflict of interest to declare.

\section{Author's Contribution}

SKL: Conceptualization, Methodology, Investigation, Data curation, Formal analysis, Writingoriginal draft, and Funding acquisition. SOO: Conceptualization, Methodology, and Investigation. AD: Methodology, Validation, Investigation, Formal analysis, and Writing- original draft. OSF: Formal analysis, Validation, Visualization and Writing- Review \&Editing. ESN: Resources and Visualization, Writing- Review \&Editing and supervision. COR: Resources, Supervision, Project administration, Writing- Review \&Editing and Funding acquisition OOA: Conceptualization, Writing- Review and editing

\section{Acknowledgement}

The authors appreciate the technical support from Biomedical Research Unit (BRU) staff and School of chemistry and physics, natural product laboratory of University of KwaZulu-Natal

\section{References}

Aebi, H. (1974). Catalase. In Methods of enzymatic analysis (pp. 673-684). Elsevier. https://doi.org/http://dx.doi.org/10.1016/S0076-6879(84)05016-3

Alkaladi, A., Abdelazim, A. M., \& Afifi, M. (2014). Antidiabetic activity of zinc oxide and silver nanoparticles on streptozotocin-induced diabetic rats. Int J Mol Sci, 15(2), 2015-2023. https://doi.org/10.3390/ijms15022015

Anthony, I. C., Ramage, S. N., Carnie, F. W., Simmonds, P., \& Bell, J. E. (2005). Influence of HAART on HIVrelated CNS disease and neuroinflammation. J Neuropathol Exp Neurol, 64(6), 529-536. https://doi.org/10.1093/jnen/64.6.529 
Avari, P., \& Devendra, S. (2017). Human immunodeficiency virus and type 2 diabetes. London J Prim Care (Abingdon), 9(3), 38-42. https://doi.org/10.1080/17571472.2017.1302872

Bădescu, S., Tătaru, C., Kobylinska, L., Georgescu, E., Zahiu, D., Zăgrean, A., \& Zăgrean, L. (2016). Effects of caffeine on locomotor activity in streptozotocin-induced diabetic rats. Journal of medicine and life, 9(3), 275.

Berkowitz, R. L., Coplan, J. D., Reddy, D. P., \& Gorman, J. M. (2007). The human dimension: how the prefrontal cortex modulates the subcortical fear response. Rev Neurosci, 18(3-4), 191-207. https://doi.org/10.1515/revneuro.2007.18.3-4.191

Burdusel, A. C., Gherasim, O., Grumezescu, A. M., Mogoanta, L., Ficai, A., \& Andronescu, E. (2018). Biomedical Applications of Silver Nanoparticles: An Up-to-Date Overview. Nanomaterials (Basel), 8(9). https://doi.org/10.3390/nano8090681

Cavalcante, G. I., Chaves Filho, A. J., Linhares, M. I., de Carvalho Lima, C. N., Venancio, E. T., Rios, E. R., de Souza, F. C., Vasconcelos, S. M., Macedo, D., \& de Franca Fonteles, M. M. (2017). HIV antiretroviral drug Efavirenz induces anxiety-like and depression-like behavior in rats: evaluation of neurotransmitter alterations in the striatum. Eur J Pharmacol, 799, 7-15. https://doi.org/10.1016/j.ejphar.2017.02.009

Charlton, R. A., Lamar, M., Zhang, A., Ren, X., Ajilore, O., Pandey, G. N., \& Kumar, A. (2018). Associations between pro-inflammatory cytokines, learning, and memory in late-life depression and healthy aging. Int J Geriatr Psychiatry, 33(1), 104-112. https://doi.org/10.1002/gps.4686

Checa, A., Castillo, A., Camacho, M., Tapia, W., Hernandez, I., \& Teran, E. (2020). Depression is associated with efavirenz-containing treatments in newly antiretroviral therapy initiated HIV patients in Ecuador. AIDS Res Ther, 17(1), 47. https://doi.org/10.1186/s12981-020-00303-1

Chen, Y. F., Stampley, J. E., Irving, B. A., \& Dugas, T. R. (2019). Chronic Nucleoside Reverse Transcriptase Inhibitors Disrupt Mitochondrial Homeostasis and Promote Premature Endothelial Senescence. Toxicol Sci, 172(2), 445-456. https://doi.org/10.1093/toxsci/kfz203

Cohen, J., D'Agostino, L., Wilson, J., Tuzer, F., \& Torres, C. (2017). Astrocyte Senescence and Metabolic Changes in Response to HIV Antiretroviral Therapy Drugs. Front Aging Neurosci, 9, 281. https://doi.org/10.3389/fnagi.2017.00281

Coleman, E., Judd, R., Hoe, L., Dennis, J., \& Posner, P. (2004). Effects of diabetes mellitus on astrocyte GFAP and glutamate transporters in the CNS. Glia, 48(2), 166-178. https://doi.org/10.1002/glia.20068

Crumeyrolle-Arias, M., Jaglin, M., Bruneau, A., Vancassel, S., Cardona, A., Dauge, V., Naudon, L., \& Rabot, S. (2014). Absence of the gut microbiota enhances anxiety-like behavior and neuroendocrine response to acute stress in rats. Psychoneuroendocrinology, 42, 207-217. https://doi.org/10.1016/i.psyneuen.2014.01.014

Djidja, M. C., Claude, E., Scriven, P., Allen, D. W., Carolan, V. A., \& Clench, M. R. (2017). Antigen retrieval prior to on-tissue digestion of formalin-fixed paraffin-embedded tumour tissue sections yields oxidation of proline residues. Biochim Biophys Acta Proteins Proteom, 1865(7), 901-906. https://doi.org/10.1016/i.bbapap.2016.11.019 
Dlugosz, O., Szostak, K., Staron, A., Pulit-Prociak, J., \& Banach, M. (2020). Methods for Reducing the Toxicity of Metal and Metal Oxide NPs as Biomedicine. Materials (Basel), 13(2). https://doi.org/10.3390/ma13020279

Eilam, D. (2003). Open-field behavior withstands drastic changes in arena size. Behavioural Brain Research, 142(1-2), 53-62. https://doi.org/10.1016/s0166-4328(02)00382-0

Ellman, G. L. (1959). Tissue sulfhydryl groups. Archives of biochemistry and biophysics, 82(1), 70-77.

Ergin, H. E., Inga, E. E., Maung, T. Z., Javed, M., \& Khan, S. (2020). HIV, Antiretroviral Therapy and Metabolic Alterations: A Review. Cureus, 12(5), e8059. https://doi.org/10.7759/cureus.8059

Everson, F., Genis, A., Ogundipe, T., De Boever, P., Goswami, N., Lochner, A., Blackhurst, D., \& Strijdom, H. (2018). Treatment with a fixed dose combination antiretroviral therapy drug containing tenofovir, emtricitabine and efavirenz is associated with cardioprotection in high calorie dietinduced obese rats. PLoS One, 13(12), e0208537. https://doi.org/10.1371/journal.pone.0208537

Ferdous, Z., \& Nemmar, A. (2020). Health Impact of Silver Nanoparticles: A Review of the Biodistribution and Toxicity Following Various Routes of Exposure. Int J Mol Sci, 21(7). https://doi.org/10.3390/ijms21072375

Govender, S., Lutchman, D., Pillay, V., Chetty, D. J., \& Govender, T. (2006). Enhancing drug incorporation into tetracycline-loaded chitosan microspheres for periodontal therapy. J Microencapsul, 23(7), 750-761. https://doi.org/10.1080/02652040600789229

Greish, K., Alqahtani, A. A., Alotaibi, A. F., Abdulla, A. M., Bukelly, A. T., Alsobyani, F. M., Alharbi, G. H., Alkiyumi, I. S., Aldawish, M. M., Alshahrani, T. F., Pittala, V., Taurin, S., \& Kamal, A. (2019a). The Effect of Silver Nanoparticles on Learning, Memory and Social Interaction in BALB/C Mice. Int J Environ Res Public Health, 16(1), 148. https://doi.org/10.3390/ijerph16010148

Greish, K., Alqahtani, A. A., Alotaibi, A. F., Abdulla, A. M., Bukelly, A. T., Alsobyani, F. M., Alharbi, G. H., Alkiyumi, I. S., Aldawish, M. M., Alshahrani, T. F., Pittala, V., Taurin, S., \& Kamal, A. (2019b). The Effect of Silver Nanoparticles on Learning, Memory and Social Interaction in BALB/C Mice. Int J Environ Res Public Health, 16(1). https://doi.org/10.3390/ijerph16010148

Hall, C. S. (1934). Emotional behavior in the rat. I. Defecation and urination as measures of individual differences in emotionality. Journal of Comparative Psychology, 18(3), 385-403. https://doi.org/10.1037/h0071444

Han, C. Y. (2016). Roles of Reactive Oxygen Species on Insulin Resistance in Adipose Tissue. Diabetes Metab J, 40(4), 272-279. https://doi.org/10.4093/dmj.2016.40.4.272

Hare, B. D., \& Duman, R. S. (2020). Prefrontal cortex circuits in depression and anxiety: contribution of discrete neuronal populations and target regions. Mol Psychiatry, 25(11), 2742-2758. https://doi.org/10.1038/s41380-020-0685-9

Heaton, R. K., Franklin, D. R., Ellis, R. J., McCutchan, J. A., Letendre, S. L., Leblanc, S., Corkran, S. H., Duarte, N. A., Clifford, D. B., Woods, S. P., Collier, A. C., Marra, C. M., Morgello, S., Mindt, M. R., Taylor, M. J., Marcotte, T. D., Atkinson, J. H., Wolfson, T., Gelman, B. B., McArthur, J. C., Simpson, D. M., Abramson, I., Gamst, A., Fennema-Notestine, C., Jernigan, T. L., Wong, J., Grant, I., Group, C., \& Group, H. (2011). HIV-associated neurocognitive disorders before and during the era of combination antiretroviral therapy: differences in rates, nature, and predictors. $J$ Neurovirol, 17(1), 3-16. https://doi.org/10.1007/s13365-010-0006-1 
Hulgan, T., Morrow, J., D'Aquila, R. T., Raffanti, S., Morgan, M., Rebeiro, P., \& Haas, D. W. (2003). Oxidant stress is increased during treatment of human immunodeficiency virus infection. Clin Infect Dis, 37(12), 1711-1717. https://doi.org/10.1086/379776

Iravani, S., Korbekandi, H., Mirmohammadi, S. V., \& Zolfaghari, B. (2014). Synthesis of silver nanoparticles: chemical, physical and biological methods. Research in pharmaceutical sciences, 9(6), 385.

Kakkar, P., Das, B., \& Viswanathan, P. N. (1984). A modified spectrophotometric assay of superoxide dismutase. Indian J Biochem Biophys, 21(2), 130-132. https://www.ncbi.nlm.nih.gov/pubmed/6490072

Kenwood, M. M., Kalin, N. H., \& Barbas, H. (2021). The prefrontal cortex, pathological anxiety, and anxiety disorders. Neuropsychopharmacology. https://doi.org/10.1038/s41386-021-01109-z

Keshari, A. K., Srivastava, R., Singh, P., Yadav, V. B., \& Nath, G. (2020). Antioxidant and antibacterial activity of silver nanoparticles synthesized by Cestrum nocturnum. J Ayurveda Integr Med, 11(1), 37-44. https://doi.org/10.1016/j.jaim.2017.11.003

Kirkinezos, I. G., Bacman, S. R., Hernandez, D., Oca-Cossio, J., Arias, L. J., Perez-Pinzon, M. A., Bradley, W. G., \& Moraes, C. T. (2005). Cytochrome c association with the inner mitochondrial membrane is impaired in the CNS of G93A-SOD1 mice. J Neurosci, 25(1), 164-172. https://doi.org/10.1523/JNEUROSCl.3829-04.2005

Kumar, L., Verma, S., Prasad, D. N., Bhardwaj, A., Vaidya, B., \& Jain, A. K. (2015). Nanotechnology: a magic bullet for HIV AIDS treatment. Artif Cells Nanomed Biotechnol, 43(2), 71-86. https://doi.org/10.3109/21691401.2014.883400

Kumar, R. (2019). Lipid-based nanoparticles for drug-delivery systems. In Nanocarriers for Drug Delivery (pp. 249-284). Elsevier.

Lara, H. H., Ayala-Nunez, N. V., Ixtepan-Turrent, L., \& Rodriguez-Padilla, C. (2010). Mode of antiviral action of silver nanoparticles against HIV-1. J Nanobiotechnology, 8, 1. https://doi.org/10.1186/1477-3155-8-1

Lewden, C., Bouteloup, V., De Wit, S., Sabin, C., Mocroft, A., Wasmuth, J. C., van Sighem, A., Kirk, O., Obel, N., Panos, G., Ghosn, J., Dabis, F., Mary-Krause, M., Leport, C., Perez-Hoyos, S., SobrinoVegas, P., Stephan, C., Castagna, A., Antinori, A., d'Arminio Monforte, A., Torti, C., Mussini, C., Isern, V., Calmy, A., Teira, R., Egger, M., Grarup, J., \& Chene, G. (2012). All-cause mortality in treated HIV-infected adults with CD4 $>/=500 / \mathrm{mm} 3$ compared with the general population: evidence from a large European observational cohort collaboration. Int J Epidemiol, 41(2), 433445. https://doi.org/10.1093/ije/dyr164

Li, B., Gao, T., \& Du, J. (2019). Neuroimmune imbalance: the key for the treatment of anxiety? Journal of Immunological Sciences, 3(3).

Likhtik, E., Stujenske, J. M., Topiwala, M. A., Harris, A. Z., \& Gordon, J. A. (2014). Prefrontal entrainment of amygdala activity signals safety in learned fear and innate anxiety. Nat Neurosci, 17(1), 106113. https://doi.org/10.1038/nn.3582

Lin, S. P., Wu, C. Y., Wang, C. B., Li, T. C., Ko, N. Y., \& Shi, Z. Y. (2018). Risk of diabetes mellitus in HIVinfected patients receiving highly active antiretroviral therapy: A nationwide population-based study. Medicine (Baltimore), 97(36), e12268. https://doi.org/10.1097/MD.0000000000012268 
Lucas, S. B., Zaki, S. R., \& Portmann, B. C. (2011). Other viral and infectious diseases and HIV-related liver disease. MacSween's Pathology of the Liver. 20126th ed Philadelphia, Pennsy/vania Churchill Livingstone, 403-466.

Marin, S., Mihail Vlasceanu, G., Elena Tiplea, R., Raluca Bucur, I., Lemnaru, M., Minodora Marin, M., \& Mihai Grumezescu, A. (2015). Applications and toxicity of silver nanoparticles: a recent review. Current topics in medicinal chemistry, 15(16), 1596-1604.

Mkhwanazi, B. N., Serumula, M. R., Myburg, R. B., Van Heerden, F. R., \& Musabayane, C. T. (2014). Antioxidant effects of maslinic acid in livers, hearts and kidneys of streptozotocin-induced diabetic rats: effects on kidney function. Ren Fail, 36(3), 419-431. https://doi.org/10.3109/0886022X.2013.867799

Nansseu, J. R., Bigna, J. J., Kaze, A. D., \& Noubiap, J. J. (2018). Incidence and Risk Factors for Prediabetes and Diabetes Mellitus Among HIV-infected Adults on Antiretroviral Therapy: A Systematic Review and Meta-analysis. Epidemiology, 29(3), 431-441. https://doi.org/10.1097/EDE.0000000000000815

Nsonwu-Anyanwu, A., Ighodalo, E., King, D., Elochukwu, A., Jeremiah, S., Solomon, O., \& Usoro, C. (2017). Biomarkers of Oxidative Stress in HIV Seropositive Individuals on Highly Active Antiretroviral Therapy. Reactive Oxygen Species, 3(9), 1-11. https://doi.org/10.20455/ros.2017.827

Nuesch, R., Gayet-Ageron, A., Chetchotisakd, P., Prasithsirikul, W., Kiertiburanakul, S., Munsakul, W., Raksakulkarn, P., Tansuphasawasdikul, S., Chautrakarn, S., Ruxrungtham, K., Hirschel, B., Anaworanich, J., \& group, S. s. (2009). The impact of combination antiretroviral therapy and its interruption on anxiety, stress, depression and quality of life in Thai patients. Open AIDS J, 3, 3845. https://doi.org/10.2174/1874613600903010038

Pang, L., Lian, X., Liu, H., Zhang, Y., Li, Q., Cai, Y., Ma, H., \& Yu, X. (2020). Understanding Diabetic Neuropathy: Focus on Oxidative Stress. Oxid Med Cell Longev, 2020, 9524635. https://doi.org/10.1155/2020/9524635

Quagliato, L. A., \& Nardi, A. E. (2018). Cytokine alterations in panic disorder: A systematic review. J Affect Disord, 228, 91-96. https://doi.org/10.1016/i.jad.2017.11.094

Rabkin, J. G., Ferrando, S. J., Lin, S.-H., Sewell, M., \& McElhiney, M. (2000). Psychological effects of HAART: a 2-year study. Psychosomatic medicine, 62(3), 413-422.

Raines, C., Radcliffe, O., \& Treisman, G. J. (2005). Neurologic and psychiatric complications of antiretroviral agents. J Assoc Nurses AIDS Care, 16(5), 35-48. https://doi.org/10.1016/i.jana.2005.07.004

Romao, P. R., Lemos, J. C., Moreira, J., de Chaves, G., Moretti, M., Castro, A. A., Andrade, V. M., Boeck, C. R., Quevedo, J., \& Gavioli, E. C. (2011). Anti-HIV drugs nevirapine and efavirenz affect anxietyrelated behavior and cognitive performance in mice. Neurotox Res, 19(1), 73-80. https://doi.org/10.1007/s12640-009-9141-y

Salim, S. (2017). Oxidative Stress and the Central Nervous System. J Pharmacol Exp Ther, 360(1), 201205. https://doi.org/10.1124/ipet.116.237503 
Schank, M., Zhao, J., Moorman, J. P., \& Yao, Z. Q. (2021). The Impact of HIV- and ART-Induced Mitochondrial Dysfunction in Cellular Senescence and Aging. Cells, 10(1). https://doi.org/10.3390/cells10010174

Seethalakshmi , A. M. K. M. (2015). Evaluation of In-vitro Anti-Inflammatory Activity of Silver Nanoparticles Synthesised using Piper Nigrum Extract. Journal of Nanomedicine \& Nanotechnology, 06(02). https://doi.org/10.4172/2157-7439.1000268

Sharma, B. (2014). Oxidative stress in HIV patients receiving antiretroviral therapy. Curr HIV Res, 12(1), 13-21. https://doi.org/10.2174/1570162x12666140402100959

Siracusa, R., Fusco, R., \& Cuzzocrea, S. (2019). Astrocytes: Role and Functions in Brain Pathologies. Front Pharmacol, 10, 1114. https://doi.org/10.3389/fphar.2019.01114

Smith, J. N., Thomas, D. G., Jolley, H., Kodali, V. K., Littke, M. H., Munusamy, P., Baer, D. R., Gaffrey, M. J., Thrall, B. D., \& Teeguarden, J. G. (2018). All that is silver is not toxic: silver ion and particle kinetics reveals the role of silver ion aging and dosimetry on the toxicity of silver nanoparticles. Part Fibre Toxicol, 15(1), 47. https://doi.org/10.1186/s12989-018-0283-z

Sofroniew, M. V., \& Vinters, H. V. (2010). Astrocytes: biology and pathology. Acta Neuropathol, 119(1), 7-35. https://doi.org/10.1007/s00401-009-0619-8

Tovote, P., Fadok, J. P., \& Luthi, A. (2015). Neuronal circuits for fear and anxiety. Nat Rev Neurosci, 16(6), 317-331. https://doi.org/10.1038/nrn3945

Turkevich, J., Stevenson, P., \& Hillier, J. (1951). The size and shape factor in colloidal systems. 11, 55. https://doi.org/https://doi.org/10.1039/df9511100055

Vadlapudi, V., \& Amanchy, R. (2017). Phytofabrication of silver nanoparticles using Myriostachya wightiana as a novel bioresource, and evaluation of their biological activities. Brazilian Archives of Biology and Technology, 60(0). https://doi.org/10.1590/1678-4324-2017160329

Van Dong, P., Ha, C. H., Binh, L. T., \& Kasbohm, J. (2012). Chemical synthesis and antibacterial activity of novel-shaped silver nanoparticles. International Nano Letters, 2(1). https://doi.org/10.1186/2228-5326-2-9

Wang, X., Ji, Z., Chang, C. H., Zhang, H., Wang, M., Liao, Y. P., Lin, S., Meng, H., Li, R., Sun, B., Winkle, L. V., Pinkerton, K. E., Zink, J. I., Xia, T., \& Nel, A. E. (2014). Use of coated silver nanoparticles to understand the relationship of particle dissolution and bioavailability to cell and lung toxicological potential. Small, 10(2), 385-398. https://doi.org/10.1002/smll.201301597

Wesierska, M., Dziendzikowska, K., Gromadzka-Ostrowska, J., Dudek, J., Polkowska-Motrenko, H., Audinot, J. N., Gutleb, A. C., Lankoff, A., \& Kruszewski, M. (2018). Silver ions are responsible for memory impairment induced by oral administration of silver nanoparticles. Toxicol Lett, 290, 133-144. https://doi.org/10.1016/j.toxlet.2018.03.019

Wilson, R. D., \& Islam, M. S. (2012). Fructose-fed streptozotocin-injected rat: an alternative model for type 2 diabetes. Pharmacol Rep, 64(1), 129-139. https://doi.org/10.1016/s1734-1140(12)70739$\underline{9}$

Yang, Y., Liu, X., Wu, T., Zhang, W., Shu, J., He, Y., \& Tang, S. J. (2018). Quercetin attenuates AZT-induced neuroinflammation in the CNS. Sci Rep, 8(1), 6194. https://doi.org/10.1038/s41598-018-24618-2 
Zhang, D., Xiao, Q., Luo, H., \& Zhao, K. (2015). Effects of angiotensin-(1-7) on hippocampal expressions of GFAP and GDNF and cognitive function in rats with diabetes mellitus. Nan fang yi ke da xue xue bao= Journal of Southern Medical University, 35(5), 646-651. 